A. V. Arzhannikov ${ }^{1,2}$, A. V. Burdakov ${ }^{1-3}$, P. V. Kalinin ${ }^{1,2}$, S. A. Kuznetsov ${ }^{1,2}$, M. A. Makarov ${ }^{1}$, K. I. Mekler $^{1}$, S. V. Polosatkin ${ }^{1,2}$, V. V. Postupaev ${ }^{1,2}$, A. F. Rovenskikh ${ }^{1}$, S. L. Sinitsky ${ }^{1,2}$, V. F. Sklyarov ${ }^{1,3}$, V. D. Stepanov ${ }^{1,2}$, Yu. S. Sulyaev ${ }^{1}$, M. K. A. Thumm ${ }^{4}$, L. N. Vyacheslavov ${ }^{1,2}$

1 Budker Institute of Nuclear Physics SB RAS Lavrent'ev Ave. 11, Novosibirsk, 630090, Russia

${ }^{2}$ Novosibirsk State University

Pirogova Str. 2, Novosibirsk, 630090, Russia

${ }^{3}$ Novosibirsk State Technical University Karl Marx Ave. 20, Novosibirsk, 630090, Russia

${ }^{4}$ Karlsruhe Institute of Technology Hertzstrasee, 16a, 76187, Karlsruhe, Germany

E-mail: physics@vestnik.nsu.ru

\title{
SUBTERAHERTZ GENERATION BY STRONG LANGMUIR TURBULENCE AT TWO-STREAM INSTABILITY OF HIGH CURRENT 1-MeV REBS
}

The results of investigation for subterahertz radiation emission induced by strong Langmuir turbulence driven by a microsecond relativistic electron beam are presented. The radiation is associated with a plasmon-plasmon merging process, which generates photons at a double plasma frequency in the range of few hundreds $\mathrm{GHz}$.

Keywords: Langmuir turbulence, plasmon-plasmon merging, subterahertz emission, plasma diagnostics.

А. В. Аржанников, А. В. Бурдаков, П. В. Калинин, С. А. Кузнецов, М. А. Макаров, К. И. Меклер, С. В. Полосаткин, В. В. Поступаев, А. Ф. Ровенских, С. Л. Синицкий, В. Ф. Скляров, В. Д. Степанов, Ю. С. Суляев, М. К. А. Тумм, Л. Н. Вячеславов

\section{ГЕНЕРАЦИЯ СУБТЕРАГЕРЦОВОГО ИЗЛУЧЕНИЯ СИЛЬНОЙ ЛЕНГМЮРОВСКОЙ ТУРБУЛЕНТНОСТЬЮ ПРИ ДВУХПОТОКОВОЙ НЕУСТОЙЧИВОСТИ СИЛЬНОТОЧНОГО 1-МЭВ РЭП}

\footnotetext{
Представлены результаты исследования эмиссии субтерагерцового излучения, индуцированного сильной ленгмюровской турбулентностью, накачиваемой микросекундным релятивистским электронным пучком. Излучение связывается с процессом плазмон-плазмонного слияния, приводящего к генерации фотонов на двойной плазменной частоте в диапазоне нескольких сотен ГГц.

Ключевые словаs: ленгмюровская турбулентность, плазмон-плазмонное слияние, субтерагерцовая эмиссия, диагностика плазмы
}

\section{Introduction and background}

One of the possible ways to generate submillimeter and terahertz radiation is to use a process of transformation of plasma waves into electromagnetic radiation at strong Langmuir turbulence pumped by a high current relativis- tic electron beam in a plasma column. An efficient mechanism to obtain the high power submillimeter radiation at the beam-plasma interaction is based on the process of merging two Langmuir plasmons, which generates photons with the frequency twice larger than the plasmon's one.

ISSN 1818-7994. Вестник НГУ. Серия: Физика. 2010. Том 5, выпуск 4

Vestnik Novosibirsk State University. Series: Physics. 2010. Volume 5, issue 4

(C) A. V. Arzhannikov, A. V. Burdakov, P. V. Kalinin, S. A. Kuznetsov,

M. A. Makarov, K. I. Mekler, S. V. Polosatkin, V. V. Postupaev, A. F. Rovenskikh, S. L. Sinitsky,

V.F. Sklyarov, V. D. Stepanov, Yu. S. Sulyaev, M. K. A. Thumm, L. N. Vyacheslavov, 2010 
In the experiments at the GOL-3 facility $[1 ; 2]$, wherein the plasma is heated by a $10 \mathrm{mi}-$ crosecond REB, the electron temperature reaches $1-2 \mathrm{keV}$ at the bulk plasma density $n \approx 10^{14}-10^{15} \mathrm{~cm}^{-3}$. The mechanism of plasma heating at the GOL-3 facility is recognized as the excitation of strong Langmuir turbulence (LT) via a two-stream instability induced by the propagating high current REB [3]. Due to this mechanism of the plasma heating a significant fraction of the beam energy can be converted into the electromagnetic radiation emitted from the plasma column. Our long-standing plasma heating experiments with submicrosecond Ebeams $\left(1-10 \mathrm{kA} / \mathrm{cm}^{2}, \tau_{b} \sim 100 \mathrm{~ns}\right)$ showed that the LT energy density $W_{l}$ at the strong beamplasma interaction may reach a relatively high values (limited by nonlinear processes): $W_{l} / n T \sim 10^{-1}$, where $n T$ is the energy density of the heated plasma electrons [3].

The detailed theoretical consideration of LT-induced electromagnetic emission from turbulent plasmas, verified by astronomical observations of solar radio-flares [4], distinguishes two main processes responsible for the electromagnetic radiation emission during the REB-plasma interaction at GOL-3. First, plasmon scattering on plasma density fluctuations yields electromagnetic emission at the plasma frequency $\omega_{p}\left(\right.$ “ $\omega_{p}$-process"). Second, plasmonplasmon merging results in production of photons in the vicinity of the double plasma frequency $2 \omega_{p}$ (" $2 \omega_{p}$-process"). For plasma densities $10^{14}-10^{15} \mathrm{~cm}^{-3}$, the output radiation frequencies associated with the aforementioned processes are located in the range of millimeter-submillimeter waves:

$$
\begin{aligned}
\omega_{p} / 2 \pi & \cong 90-283 \mathrm{GHz}, \\
2 \omega_{p} / 2 \pi & \cong 180-566 \mathrm{GHz} .
\end{aligned}
$$

In this paper, we present the first observation of LT-induced submillimeter-wave emission from GOL-3 plasma during injection of the $10 \mu \mathrm{s}-\mathrm{REB}$. At the current stage of research, we intentionally focused on investigating $2 \omega_{p^{-}}$ emission, since plasma is more transparent at the double plasma frequency compared to the $\omega_{p}$-emission. The results are obtained via an original radiometric diagnostics specially elaborated for spectral measurements in the band $250-430 \mathrm{GHz}$ near the middle frequencies of the " $2 \omega_{p}$-process".

\section{Experimental set up}

Experimental studies were carried out at the multimirror magnetic trap GOL-3, where a long $(12 \mathrm{~m})$ plasma column is confined in a strong corrugated magnetic field $\left(\mathrm{B}_{\max } / \mathrm{B}_{\min } \cong\right.$ $\cong 4.8 / 3.2 \mathrm{~T}$ ). The electron beam with the current up to $20 \mathrm{kA} / \mathrm{cm}^{2}$ and the particle energy up to $0.8 \mathrm{MeV}$ is injected during $10 \mu$ s through the left end of the plasma column as it is shown in Fig. 1.

Measurements of the $2 \omega_{\mathrm{p}}$-emission were performed at the distance of about $80 \mathrm{~cm}$ from the beam injection plane $(B \cong 4 T)$ where the maximum efficiency for the beam-plasma interaction is identified from diamagnetic signals. The radiation output from the plasma chamber was carried out perpendicularly to the axis of the GOL-3 solenoid through a teflon window with the aperture size $70 \times 30 \mathrm{~mm}$ joined with a quasi-optical transmission line. The latter was implemented as a hollow vertically mounted dielectric tube with diameter $\varnothing 54 \mathrm{~mm}$ and used for transporting the radiation to the radiometric system installed on a screened diagnostic bench. On the opposite side of the plasma chamber, an auxiliary teflon window was installed to minimize spurious re-reflections of submm-waves coming from the plasma regions beyond the direct "line of sight" of the radiometric system.

We developed an original 4-channel radiometric system capable of measuring power of submm-emission in four parallel frequencyshifted spectral bands $[5,6]$. We used the filters with bandwidth $\sim 40 \mathrm{GHz}$ and $-20-30 \mathrm{~dB}$ outof-band attenuation at $35-38 \mathrm{GHz}$ frequency shift of adjacent transmission bands. After passing through the filters, the $\mathrm{X}$ - and $\mathrm{Y}$ polarized sub-beams undergo the final demultiplexing and are further focused by aspheric teflon lenses $(f=40 \mathrm{~mm}, C A \varnothing 70 \mathrm{~mm})$ into the receiving horn antennas of the Shottkydetectors units. The antennas are implemented as waveguide transitions from the outer oversized cross-section $3.6 \times 1.8 \mathrm{~mm}$ onto the inner waveguide cross-section $0.72 \times 0.36 \mathrm{~mm}$ of the detector. Detection of the submm-wave signal is provided by a beam-lead GaAs Shottky diode integrated into a microstrip line used for wideband "waveguide-diode" matching. Each detector, initially developed for operation at frequencies $210-450 \mathrm{GHz}$, is equipped with 


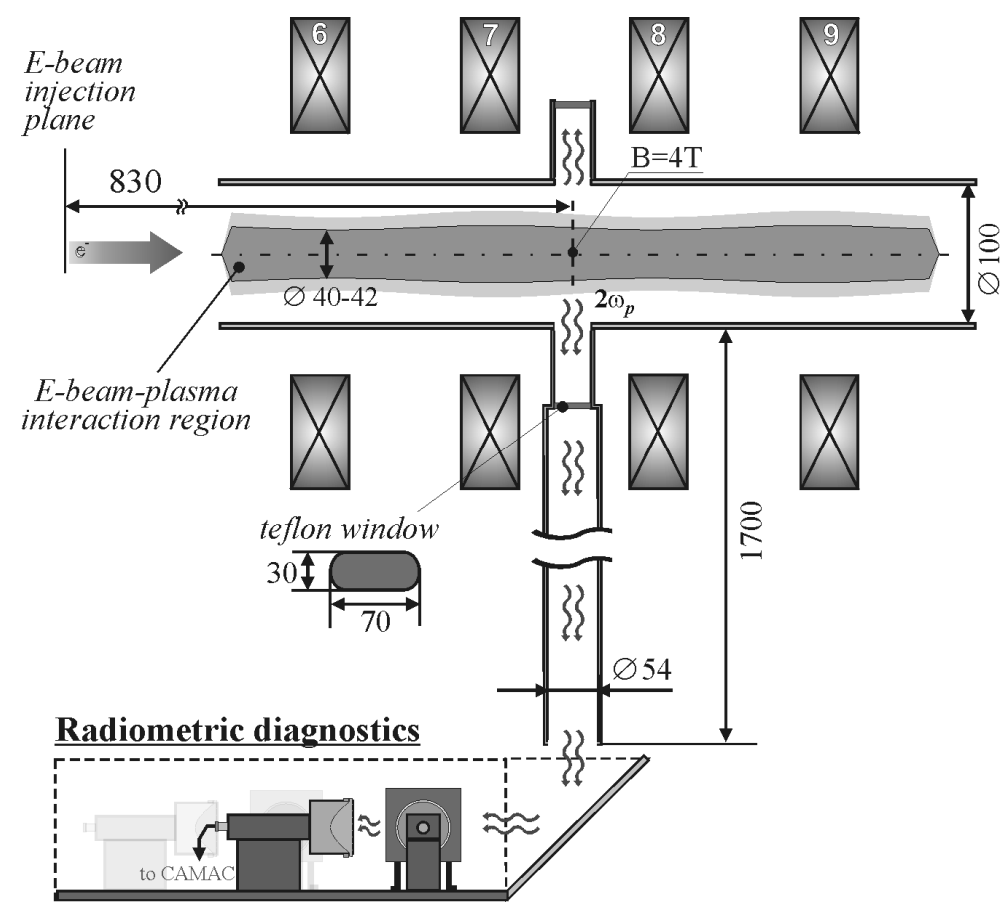

Fig. 1. Schematic of the radiometric experiment at the GOL-3 facility. All dimensions are given in mms

a built-in $900 \mathrm{MHz}$-band operational preamplifier and has the response time better than 2 ns. At $50 \Omega$ loading resistance, the typical values of the detector volt-watt sensitivity and dynamic range precisely measured with calibrated $280 \mathrm{GHz}$-solid-state radiation-source are within 1000-4000 V/W and $50 \mathrm{~dB}$, respectively. The broadband calibration of the detectors by means of a tunable backward-wave oscillator showed an acceptable level of their sensitivity up to $\sim 530 \mathrm{GHz}$.

\section{Experimental results and discussion}

For standard regimes of REB-plasma heating (the beam current up to $20 \mathrm{kA} / \mathrm{cm}^{2}$, the electron energy $0.6-0.8 \mathrm{MeV}$, and the pulse duration about $10 \mu \mathrm{s}$ ) a series of radiometric measurements of $2 \omega_{p}$-emission from GOL-3 plasma was carried out. The experiments revealed a significant level of emission during the beam injection with total duration $10 \mu \mathrm{s}$ (Fig. 2-3), which sometimes exceeded saturation level of Shottky-detectors.

The experiments demonstrated a good concordance between the estimated value of the initial plasma density and the maximum of the power spectral density of emission asso- ciated with the " $2 \omega_{p}$-process" (Fig. 3). Inspection of the $2 \omega_{p}$-emission polarization via a gridpolarizer mounted at the radiometry system entry showed predominance by a factor of 2-3 for radiation polarized transversely to the magnetic field. We also observed a phenomena of detuning and broadening of the $2 \omega_{p}$-emission spectrum typically $4-5 \mu$ s after the beam injection start (Fig. 3). It occurs due to heatinginduced modulation of the plasma density as established via Thomson scattering [7].

The performed analysis of submm-signal in time domain revealed the presence of sharp spikes of emission with 2-10 ns duration against the $0.1-1 \mu \mathrm{s}$ background envelope (Fig. 3, 4). The spikes exhibit fast spectral detuning and are admittedly associated with dynamic density dips (caverns) which emerge at the final stage of Langmuir turbulence. It is noteworthy that the fine temporal structure of the emission was distinctively enhanced for the experiments with decreased E-beam crosssection $\varnothing 1 \mathrm{~cm}$ (Fig. 4), as compared to the case of a full-size beam $(\varnothing 4 \mathrm{~cm}$, Fig. 3). This fact is associated with a smaller total number of caverns per a beam-plasma-interaction region that results on average in stronger amplitude excursion of submm-signals when caverns dynamically evolve. 
Fig. 2. Typical waveforms of the REB-accelerator diode voltage, E-beam current, plasma diamagnetism and X-ray emission (top), and spectral signals of submmradiation (bottom) at initial plasma density $n_{0} \approx 2.5 \cdot 10^{14} \mathrm{~cm}^{-3}$. A signal at $385 \mathrm{GHz}$ is zero-level and not shown. E-beam diameter in the plasma column is $4 \mathrm{~cm}$

Fig. 3. Illustration of the "blue shift" in the submm-emission spectrum due to increasing the initial plasma density:
a) $n_{0} \approx 2 \cdot 10^{14} \mathrm{~cm}^{-3}$;
b) $n_{0} \approx 4 \cdot 10^{14} \mathrm{~cm}^{-3}$
( $\varnothing 4 \mathrm{~cm})$

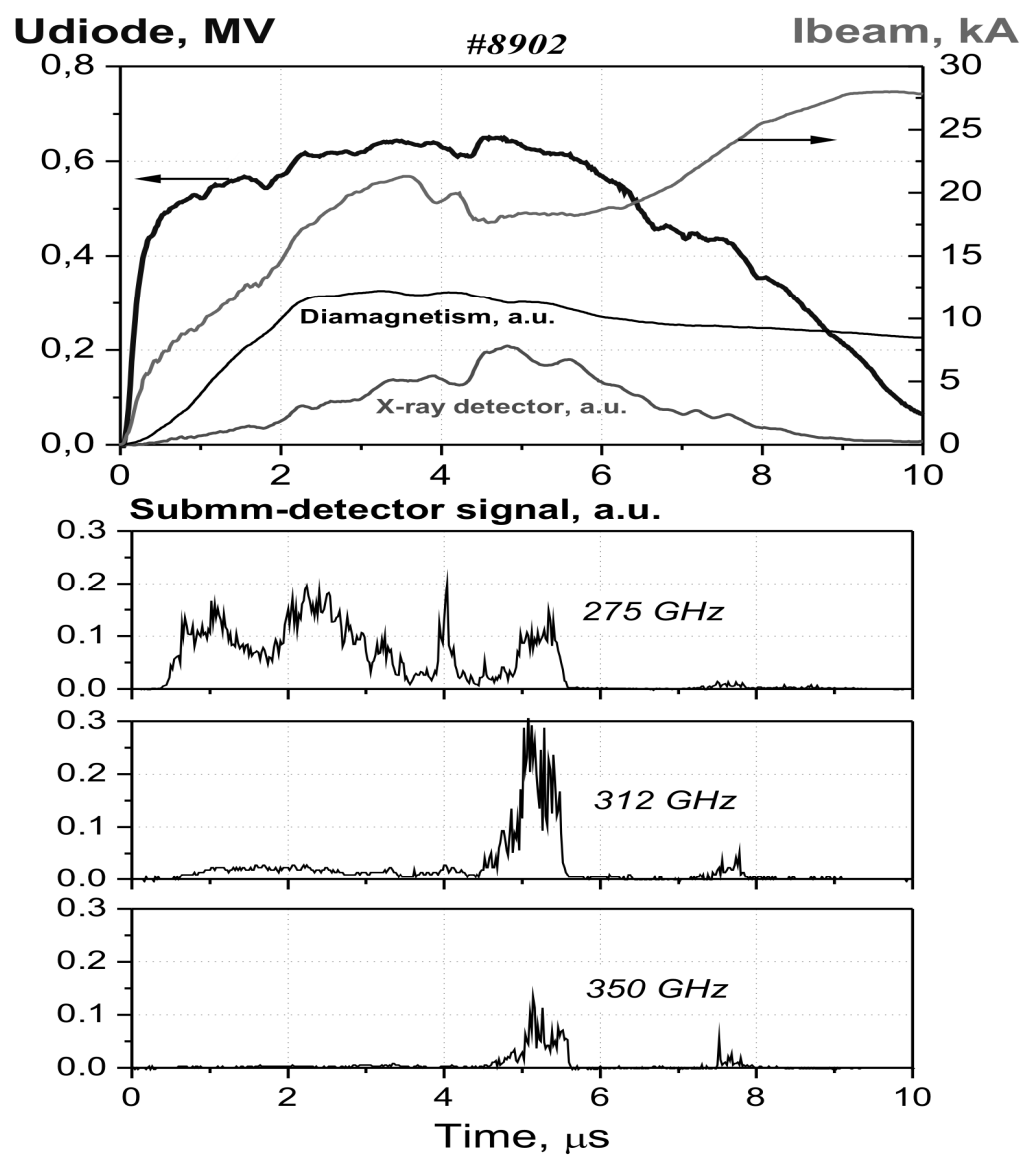

a)

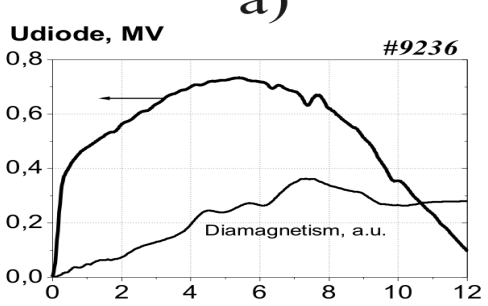

0,2 Submm-detector signal, a.u.

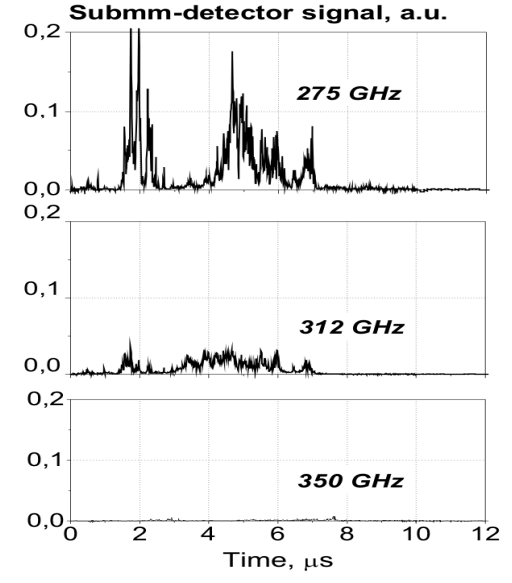

b)

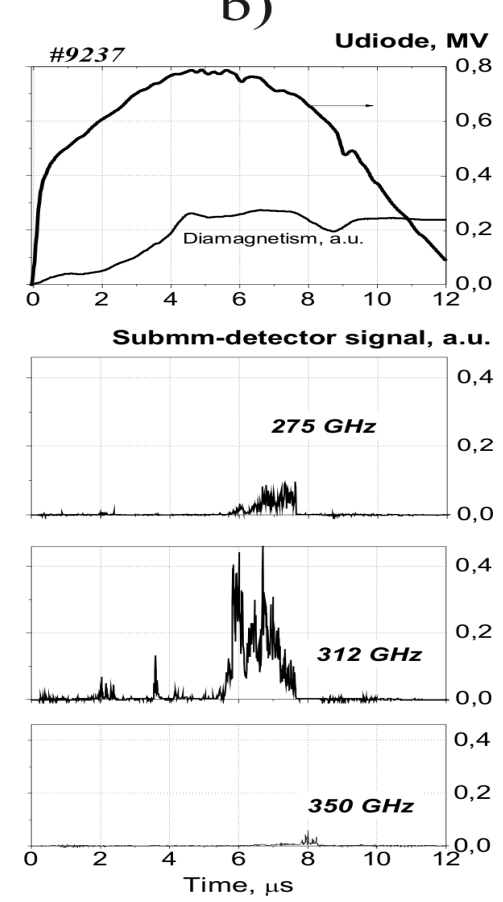




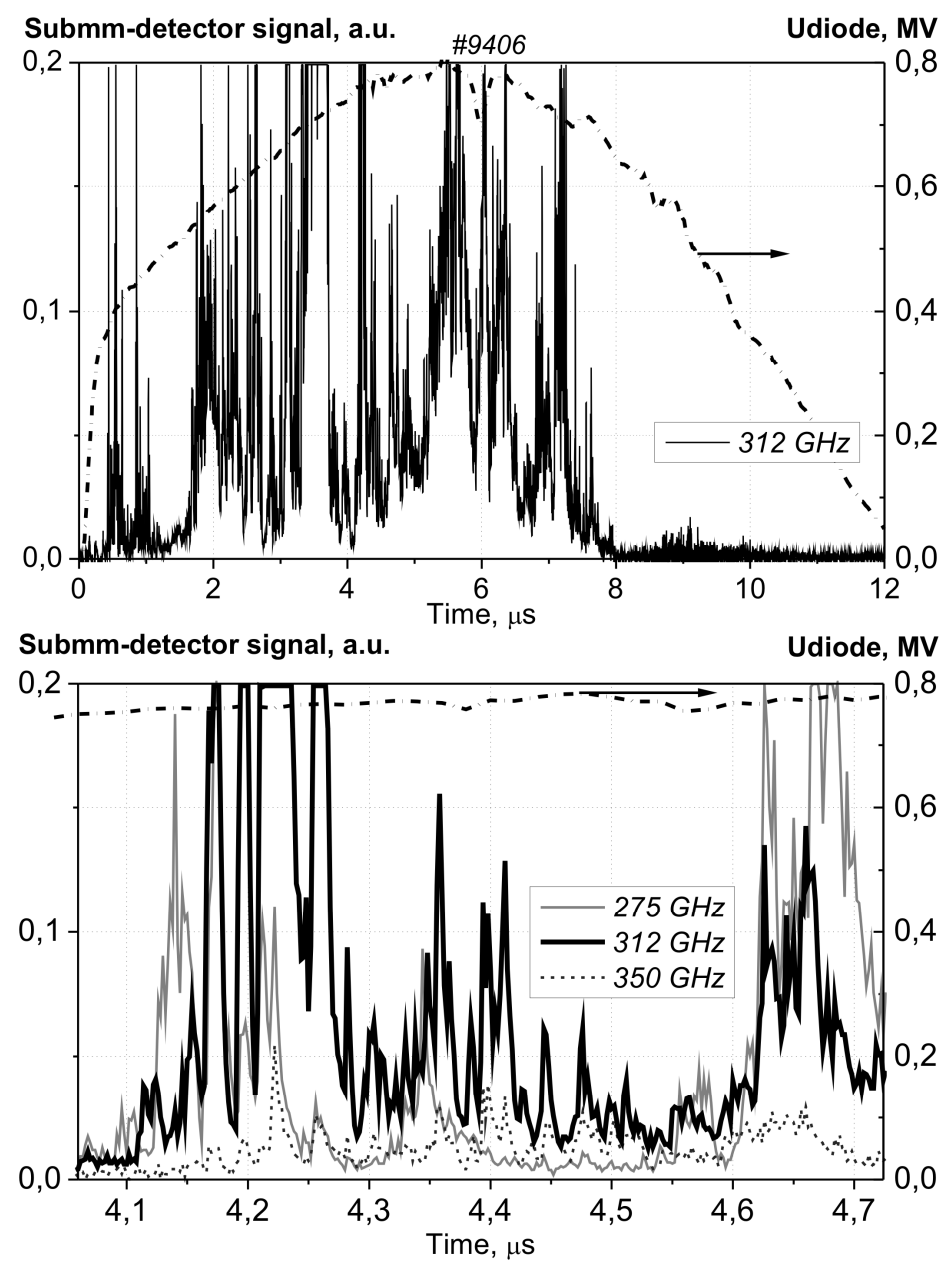

Fig. 4. An example of the shot with a fine temporal structure of submmemission obtained for the case of Ebeam with decreased transverse crosssection $(\varnothing 1 \mathrm{~cm})$. Top and bottom figures represent different time scales

Retrieved via experiment geometry, a specific power of emission was measured on the level of $\sim 100 \mathrm{~W} / \mathrm{cm}^{3}$ that conforms to theoretical estimation on the base of analytical formulas given in Ref. 4. The radiometric signals disappeared after termination of the REB injection into plasma. It also was at zero-level for the test experiments with REB injection into vacuum. Hence, a cyclotron emission from REB and plasma electrons can be ignored.

\section{Summary}

In this paper the laboratory investigations of submm-wave emission produced at strong Langmuir turbulence driven by a high-current $10 \mu$ s relativistic electron beam were realized for the first time. The emission associated with a plasmon-plasmon merging process is con- firmed by means of the originally developed multichannel radiometric diagnostics. The diagnostics was used for measuring power spectral density at frequencies $250-420 \mathrm{GHz}$. The experiments revealed a significant level of emission during the major part of beam injection time at a specific emission power value $\sim 100 \mathrm{~W} / \mathrm{cm}^{3}$ and the prevailing component of polarization transverse to the magnetic field. Measurements showed presence of slow (0.1$1 \mu \mathrm{s})$ and fast (2-10 ns) spectral detuning associated with plasma density modulations.

\section{Acknowledgments}

This work was partially supported by the grant RNP 2.1.1/3983 of the Russian Ministry of Education and Science, and the grant 
11.G34.31.0033 of the Russian Federation Government.

\section{References}

1. A. V. Burdakov et al., "Plasma heating and confinement in GOL-3 multimirror trap", Fusion Sci. and Tech., 51, no. 2T, 106 (2007).

2. A. V. Burdakov et al., "Status and prospects of GOL-3 multiple-mirror trap", Fusion Sci. and Tech., 55, no. 2T, 63-70 (2009).

3. A. V. Arzhannikov, A. V. Burdakov, V. S. Koidan, L. N. Vyacheslavov, "Physics of REB-Plasma Interaction", Physica Scripta, T2'2, 303-309 (1982).

4. E. N. Kruchina, R. Z. Sagdeev, $V$. D. Shapiro, "Strong Langmuir turbulence as a source of radio emission", JETP Lett., 32, no. 6, 419-423 (1980).

5. S. A. Kuznetsov, A. V. Arzhannikov, A. V. Gelfand, A. V. Zorenko, B. P. Gorshunov "Multichannel radiometric system for registering submillimeter-wave radiation at beamplasma interaction, NSU Bulletin. Series: Physics, Vol. 5, no. 3, 5-19 (2010).

6. S. A. Kuznetsov et al., "Development and Characterization of Quasi-Optical Mesh Filters and Metastructures for Subterahertz and Terahertz Applications", Key Eng. Materials, 437, 276-280 (2010).

7. V. S. Koidan et al., "Progress in multimirror trap GOL-3", Fusion Sci. and Tech., 47, no. $1 \mathrm{~T}, 35$ (2005).

15.09.2010 